\section{A DIAGNOSTIC DEVICE FOR ORAL AND PHARYNGEAL EXAMINATIONS OF CHILDREN - FOLDING-SCOPE FOR THE ORAL AND PHARYNGEAL CAVITIES}

\section{K. Tsunoda ${ }^{1}$, T. Sasaki ${ }^{2}$, Y. Taniguchi ${ }^{3}$}

${ }^{1}$ Artificial Organs \& Medical Device Creation, National Institute of Sensory Organs, National Hospital Organization, ${ }^{2}$ Tokyo Medical Kita Syakaihoken Hospital, ${ }^{3}$ Hoya PENTAX, Tokyo, Japan

Although children may dislike and/or resist oral and pharyngeal examination with a tongue depressor, they enjoy lollipops on sticks, eating with spoons, forks, and chopsticks, and brushing their teeth. Many reports have noted this apparent contradiction, since pediatric patients are often treated after toothbrushes or chopsticks penetrate the pharyngeal wall. Those critical reports suggested that it is important to consider psychological factors when examining the oral cavity and pharynx.

We therefore developed a novel device to observe the inside of the mouth without using a flashlight, tongue depressor, or head mirror. Now we developed a new attachment to the AWS (special electrical fiberscopy for tracheal intubation through the mouth for anesthesia and emergency situations; PENTAX Co., Tokyo, Japan) for observations inside the oral cavity and pharynx. Our newly system is a useful tool not only for diagnostic examinations but also for treatment without causing discomfort or distress to patients and their families without gag-reflex.

\section{6}

\section{MODERN AEROSOL DELIVERY DEVICES IN PRETERM NEONATES}

S. Tiemersma ${ }^{1,2}$, R.A. van Lingen ${ }^{1}$, S.G. Devadason ${ }^{2}$, M. Nelle ${ }^{3}$, S. Minocchieri ${ }^{2}$

${ }^{1}$ Princess Amalia Department of Paediatrics, Department of Neonatology, Isala Clinics, Zwolle, The Netherlands, ${ }^{2}$ Perth Medical Aerosol Research Group, School of Paediatrics and Child Health, University of Western Australia, Perth, WA, Australia, ${ }^{3}$ Department of Paediatrics, University Hospital Bern, Inselspital, Bern, Switzerland

Background and aims: Infant respiratory distress syndrome and bronchopulmonary dysplasia are serious respiratory diseases in preterm infants. Aerosol therapy in these infants is challenging due to narrow airways, low tidal volumes, high breathing frequency, lack of cooperation and lack of specialised devices. Moreover, lung deposition is low. Our aim was to evaluate efficiency and efficacy of standard devices versus a modern aerosol delivery device.

Methods: Using salbutamol as a drug marker in 5-6 measurements for each device, we studied in an upper airway model of a 32-wks preterm infant (1750 grams) PARI Pharma's investigational eFlow ${ }^{\circledR}$ nebuliser prototype for babies (VMD $3.0 \mu \mathrm{m}$ ), a jet nebuliser (Intersurgical ${ }^{\circledR}$ Cirrus, $3.5 \mu \mathrm{m}$ VMD) and a pressurised metered dose inhaler (pMDI, GSK) with a detergent coated spacer (Aerotrach Plus $®$ ) as used in our NICU. A filter was placed below the infant model's 'trachea' to capture the drug dose that would have been deposited in the lung (lung dose). Statistics were carried out using SPSS 17.0.

Results: Lung dose (\% of nominal dose) was $1.5 \%$, $7 \%$ and $21 \%$ for the jet nebuliser, pMDI-spacer and investigational eFlow nebuliser respectively $(p<$ 0.001 ). Jet nebuliser residue was $69 \%$, and $11 \%$ for the investigational eFlow nebuliser $(p<0.001)$.

Conclusions: The lung dose was significantly lower for the jet nebuliser and pMDI-spacer compared with the investigational eFlow nebuliser, but arguably still sufficient for bronchodilator delivery. If higher lung doses are required, more specialised vibrating membrane devices, designed specifically for use in infants, might be considered.

\section{7}

\section{CLINICAL EFFECTIVENESS OF THE NEW} ECOLOGICALLY PURE MEDICATION ASTHMANOL IN CHILDREN WITH BRONCHIAL ASTHMA

\author{
R. Karseladze ${ }^{1,2}$, L. Jorjoliani ${ }^{1}$, L. Saginadze ${ }^{3}$, \\ T. Bigvava ${ }^{1}$ \\ ${ }^{1}$ Paediatrics, Tbilisi State University, Faculty \\ of Medicine, ${ }^{2}$ Allergy \& Clinical Immunology \\ Department, ${ }^{3}$ Paediatrics, Scientific Research \\ Institute of Paediatrics, Tbilisi, Georgia
}

Background: It is well known that non-specific diseases of respiratory system are at the prominent position within the structure of children's diseases. We regard that any research dealing with seek of effective medications consisting of natural components is of great significance, as these are Evidence-Based unbiased clinical research, designed in accordance with internationally accepted standards, concluding of which would 